\title{
An investigation of microstructure, hardness, tensile behaviour of a titanium alloy: Role of orientation
}

\author{
MITHUN KURUVILLA ${ }^{1}$, T S SRIVATSAN ${ }^{1 *}$, M PETRAROLI $^{2}$ and \\ LISA PARK $^{3}$ \\ ${ }^{1}$ Division of Materials Science and Engineering, Department of Mechanical \\ Engineering, The University of Akron, Akron, Ohio 44325 3903, USA \\ ${ }^{2}$ Division of Research, The TIMKEN Company, Canton, Ohio 44706 0930, USA \\ ${ }^{3}$ Department of Geology, The University of Akron, Akron, Ohio 44325 3903, USA \\ e-mail: tsrivatsan@uakron.edu
}

\begin{abstract}
In this technical paper, the microstructure, hardness, tensile deformation and final fracture behaviour of an emerging titanium alloy for performancecritical applications are presented and discussed. Both longitudinal and transverse test specimens were prepared from the as-provided sheet stock of the alloy and deformed in uniaxial tension. The yield strength and tensile strength of the alloy sheet in the transverse orientation was higher than the longitudinal orientation. The ductility of the test specimens, quantified in terms of reduction-in-cross-sectional area, was higher for the transverse specimen when compared to the longitudinal counterpart. The elongation-to-failure of the test specimens was identical in the two orientations of the sheet stock. The tensile fracture behaviour of the alloy was quantified by careful examination of the fracture surfaces in a scanning electron microscope. The intrinsic fracture features on the tensile fracture surface were discussed taking into consideration the nature of loading and contribution from intrinsic microstructural features.
\end{abstract}

Keywords. Microstructure; hardness; tensile properties; fracture behaviour.

\section{Introduction}

In the continuing era of rapid industrial revolution and economic growth, noticeable advances in the domains of basic sciences, engineering and related technologies laid emphasis on the development, emergence and use of traditional metals, their alloy counterparts, and in more recent years their composite counterparts, i.e. composites based on metal matrices. One such metal is titanium, which has grown in stature, preferential use and need during the last three decades, i.e. since the early 1970s (ASM Metals Handbook 1990; Donachie 2000). Due to its excellent mechanical properties like specific strength $\left(\sigma_{\mathrm{UTS}} / \rho\right)$, stiffness, corrosion and erosion resistance, fracture toughness, formability, capability to withstand both

${ }^{*}$ For correspondence 
high temperatures and low temperatures coupled with sustained research efforts have led to the culmination in the development of new and improved titanium alloys for a range of performance critical and high performance-related applications. The development of new and improved alloys led to its selection and use in a spectrum of industries including the sectors of aerospace, marine, chemical, biomedical, defense and even commercial products (Jacob \& Kildoff 2004; Peters et al 2003; Titanium alloys developments 2006; Boyer 1996).

Pure titanium metal has a melting point of $1675^{\circ} \mathrm{C}$ and an atomic weight of 47.9 (Askeland 2007). The density of pure titanium metal is $4.5 \mathrm{~g} / \mathrm{cm}^{3}$, which is about $60 \%$ that of steel (Donachie 2000; Askeland 2007). Further, the titanium metal and its alloy counterparts are essentially non-magnetic and offer good heat transfer capability. The excellent specific strength $\left[\sigma_{\mathrm{UTS}} / \rho\right]$ of pure titanium and its alloys at both high (in excess of $590^{\circ} \mathrm{C}$ ) and low (less than $-253^{\circ} \mathrm{C}$ ) temperatures enables it to find selection and use as an ultra high speed metal for aircraft structural components and even components of the space shuttle. The high melting point of titanium metal enables in its selection and use in turbine engines (Peters et al 2003). As recently as 2005, the Boeing Aerospace Company used 15 million pounds of the titanium metal, i.e. various alloys, in different versions of their commercial aircraft. This usage is expected to more than double when production of the 787 dream-liner commences, which in essence would have $20 \%$ of the primary structure to be the titanium metal. Apart from the BOEING Company, other manufacturers of both commercial and military aircraft will enhance their use of the titanium metal for a spectrum of high performance products. Further, since the titanium metal has excellent super plastic properties, it can easily deform to the tune of $2000 \%$ without experiencing appreciable necking and/or cracking when heated to a temperature of $925^{\circ} \mathrm{C}$ during the superplastic forming process. Preliminary trials have found that titanium can be used in conjunction with polymer matrix composites, which have grown in stature for use in aircraft structures since it is galvanically compatible coupled with offering a good match in the coefficient of thermal expansion (Wessel 2004). Also, titanium and its alloy counterparts are non-magnetic and have a lower linear coefficient of expansion and lower thermal conductivity than the widely chosen and used family of steel and the alloys of aluminum (Wessel 2004). In more recent years the automotive industry has increased its use of the titanium metal because of its performance at elevated temperatures coupled with good formability. Noticeably, the metal has minimal degradation and high oxidation resistance during long term service or extended service at elevated temperatures. In the health industry titanium finds use as implants since it is biocompatible. While the procurement of raw material, manufacturing, production, and secondary processing of the titanium alloys is expensive, the mechanical and physical properties compromise on its high cost (Donachie 2000; Moiseyev 2006).

Most noticeably, the titanium metal is allotropic and has a hexagonal close packed (HCP) $\{\alpha\}$ crystal structure at low temperatures and a body-centered cubic $(\beta)$ structure at temperatures above $885^{\circ} \mathrm{C}$. The family of titanium alloys are essentially categorized as being corrosion resistant or structural. The structural titanium alloys are classified into three categories, denoted as $\alpha, \alpha+\beta$ and the $\beta$ phase alloys. The alpha-phase alloys of titanium, which is categorized as commercially pure titanium, is relatively weak in strength but offers a combination of good corrosion resistance, good weldability, creep resistance, receptive to heat treatment coupled with ease of processing and fabrication (ASM Metals Handbook 1990; Donachie 2000). The beta-phase alloys are receptive to forging while also offering excellent fracture toughness. The dual phase, i.e. alpha + beta alloys offer a combination of excellent ductility and strength when proper heat treatment is given, which makes them stronger than the 
Table 1. Nominal Chemical composition (in weight \%) of the Ti-4 Al-2.5 V-1.5 Fe-0.25 $\mathrm{O}_{2}$ alloy.

\begin{tabular}{ccccc}
\hline $\mathrm{Al}$ & $\mathrm{V}$ & $\mathrm{Fe}$ & $\mathrm{O}$ & Titanium \\
\hline 4 & 2.5 & 1.5 & 0.25 & Balance \\
\hline
\end{tabular}

alpha-phase and beta-phase counterparts (Titanium alloys developments 2006; Boyer 1996; Askeland 2007).

In this paper, the results of a recent study on microstructure, hardness, tensile properties and final fracture behaviour of a newly emerged Ti-Al-V-Fe- $\mathrm{O}_{2}$ alloy are presented. The alloy, designated and marketed as ATI $425^{\mathrm{TM}}$ was provided as sheet stock in the annealed condition, was deformed in tension on a fully automated mechanical test machine at ambient temperature. The hardness, tensile properties and final fracture behaviour of the alloy are discussed in light of test specimen orientation, intrinsic microstructural features, nature of loading, local stress state and deformation characteristics of the alloy microstructure.

\section{Material}

The ATI $425^{\mathrm{TM}}$ titanium is categorized as being a versatile alloy having higher strength than the commercial Ti-3Al-2.5V alloy and a strength comparable with the work-horse and widely chosen and used alloy Ti-6Al-4V. The alloy was provided by Allegheny Technologies Wah Chang (based in Oregon, USA) as sheet stock in the annealed condition. The nominal chemical composition of the as provided Ti-Al-V-Fe- $\mathrm{O}_{2}$ alloy is given in table 1 . This alloy was initially developed for hot-rolled armor plate to provide ballistic protection comparable to the workhorse alloy Ti-6Al-4V. Preliminary ballistic tests revealed this alloy to be very robust. Further, this alloy is noticeably less expensive than the commercial alloy Ti-6Al-4V since it uses lower cost iron as the beta stabilizing element to replace vanadium. Also, during both primary and secondary processing the alloy is hot workable and does not have many variables influencing the operations like the variables in the processing of the Ti-6Al-4V alloy. Noticeably, the alloy of interest flowed much easier during bulk forging and controlled rolling operations than alloy Ti-6Al-4V and was less prone to surface cracking thus necessitating the need for a lesser degree of surface conditioning during subsequent working operations (Srivatsan \& Kuruvilla 2007). The low oxygen content in this titanium alloy allows for twinning deformation and thereby enhancing formability. Also, the presence of aluminum contributes to increasing the strength of the alloy at both room $(298 \mathrm{~K})$ and elevated temperatures. At the atomic level, aluminum increases the stacking fault energy while suppressing twinning deformation. This makes the alloy receptive to cold deformation. Due to its outstanding corrosion resistance and other excellent mechanical properties resulted in its selection and use for products in both marine and aerospace-related industries. The American Society for Testing Materials (ASTM) has recognized this alloy and assigned to it the Grade 38.

\section{Experimental procedures}

\subsection{Sample preparation}

The tensile tests were conducted on both the longitudinal and transverse oriented test specimens that were precision machined from the as-provided mill annealed cold rolled sheet 


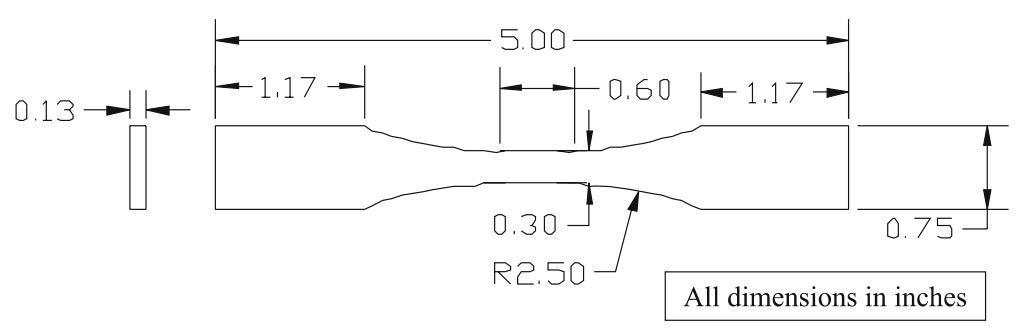

Figure 1. Schematic of the test sample.

stock. The longitudinal specimens were machined with the major stress axis parallel to the rolling direction of the alloy sheet while the transverse specimens were machined with the major axis perpendicular to the rolling direction, very much in conformance with specifications outlined in ASTM E-8 standard. The gage section had a cross-section that measured 0.3 inch by 0.125 inch with a gage length measuring 0.6 inches. The key dimensions of the test specimen are shown in figure 1. In order to minimize stress concentration arising from surface irregularities like circumferential scratches and any residual machine marks, final surface preparation was achieved by mechanically polishing the gage section of the machined test specimens with progressively finer grades of silicon carbide impregnated emery paper (320, 400 and 600 grit).

\subsection{Initial microstructure characterization}

The microstructural characterization was done on samples cut from the as-received stock of the titanium alloy using an optical microscope. The samples were mounted in bakelite and then wet ground on progressively finer grades of silicon carbide impregnated emery paper using copious amounts of water both as a lubricant and as a coolant. Subsequently, the ground sample was mechanically polished using five-micron diamond solution. Fine polishing to a perfect mirror-like finish of the surface was achieved using one-micron diamond solution as the lubricant. The polished sample of each orientation was etched using a reagent that is a solution mixture of $5 \mathrm{ml}$ of nitric acid $\left(\mathrm{HNO}_{3}\right), 10 \mathrm{ml}$ of hydrofluoric acid (HF) and $85 \mathrm{ml}$ of water $\left(\mathrm{H}_{2} \mathrm{O}\right)$. The etched surface of the polished samples was observed in an optical microscope and photographed using standard bright field illumination technique.

\subsection{Mechanical testing}

Hardness, categorized as a mechanical property of the material, is aptly defined as the resistance offered by the material to indentation, i.e. permanent deformation and cracking, was determined using a Vickers $\left(\mathrm{H}_{\mathrm{v}}\right)$ micro-hardness test machine. The hardness test is a simple, easy and non-destructive method which is an important and widely used test for the purpose of quickly quantifying or evaluating the mechanical properties of monolithic metals, their alloy counterparts and even composite materials based on metal matrices.

The Vickers $\left(\mathrm{H}_{\mathrm{v}}\right)$ micro-hardness measurements were made on a Suntech microhardness tester using an indentation load of $200 \mathrm{gm}$ for a dwell time of 11 seconds with the aid of a Vickers tool indenter. The indenter (made of diamond) has a square-base pyramidal geometry with an included angle of $136^{\circ}$. The machine makes an indent, or impression, on the sample surface whose diagonal size was measured using a low magnification optical microscope. The Vickers hardness number $\left(\mathrm{H}_{\mathrm{v}}\right)$ is the ratio of applied load to the surface area of the indent. 
Table 2. A compilation of the microhardness measurements made on the Ti-4 Al-2.5 V-1.5 $\mathrm{Fe}-0 \cdot 25 \mathrm{O}_{2}$ alloy [ATI $425^{\mathrm{TM}}$ ] (load used $=200 \mathrm{gm}$, dwell time $=11 \mathrm{sec}$ ).

\begin{tabular}{|c|c|c|c|c|c|c|c|}
\hline \multirow[b]{2}{*}{ Orientation } & & \multicolumn{6}{|c|}{ Vickers hardness-Hv } \\
\hline & & Trial-1 & Trial-2 & Trial-3 & Trial-4 & $\begin{array}{c}\text { Average } \\
\text { hardness } \\
\left(\mathrm{Kg} / \mathrm{mm}^{2}\right)\end{array}$ & $\begin{array}{c}\text { Average } \\
\text { hardness } \\
(\mathrm{GPa})\end{array}$ \\
\hline \multirow{3}{*}{ Longitudinal } & $D 1(\mu \mathrm{m})$ & 33.07 & 33.44 & $35 \cdot 32$ & $33 \cdot 25$ & - & - \\
\hline & $D 2(\mu \mathrm{m})$ & $34 \cdot 19$ & $34 \cdot 19$ & $34 \cdot 01$ & $34 \cdot 76$ & - & - \\
\hline & $\mathrm{H}_{\mathrm{v}}\left(\mathrm{Kg} / \mathrm{mm}^{2}\right)$ & 327.92 & $324 \cdot 29$ & $308 \cdot 66$ & $320 \cdot 72$ & $320 \cdot 39$ & $3 \cdot 14$ \\
\hline \multirow{3}{*}{ Transverse } & $D 1(\mu \mathrm{m})$ & $32 \cdot 88$ & $34 \cdot 01$ & $33 \cdot 82$ & 33.44 & - & - \\
\hline & $D 2(\mu \mathrm{m})$ & 33.07 & $34 \cdot 19$ & $34 \cdot 19$ & $33 \cdot 82$ & - & - \\
\hline & $\mathrm{H}_{\mathrm{v}}\left(\mathrm{Kg} / \mathrm{mm}^{2}\right)$ & $341 \cdot 13$ & 318.95 & $320 \cdot 72$ & 327.92 & $327 \cdot 18$ & $3 \cdot 2$ \\
\hline
\end{tabular}

At least four indents were made across the polished surface of a fully machined test specimen and the result is reported as the average value in units of $\mathrm{kg} / \mathrm{mm}^{2}$.

The macrohardness measurements $\left(R_{c}\right)$ were made on a Rockwell hardness machine using an indentation load of $150 \mathrm{Kgf}$ for a dwell time of 10 seconds and the corresponding value read on the ' $\mathrm{C}$ ' scale. The macrohardness tests were also done on the polished surface of both the longitudinal and transverse test specimens. The results of both the microhardness and macrohardness tests are summarized in tables 2 and 3.

Uniaxial tensile tests were performed on a fully-automated, closed-loop servo-hydraulic mechanical test machine [INSTRON-8500 Plus] using a $100 \mathrm{KN}$ load cell. The tests were conducted in the room temperature $(300 \mathrm{~K})$, laboratory air (Relative humidity of $55 \%$ ) envi-

Table 3. A compilation of the macrohardness measurements made on the Ti- $4 \mathrm{Al}-2 \cdot 5 \mathrm{~V}-1 \cdot 5 \mathrm{Fe}-0 \cdot 25$ $\mathrm{O}_{2}$ alloy [ATI $425^{\mathrm{TM}}$ ] ( $*$ - Rockwell C-Indentation load $\left.150 \mathrm{kgf}\right)$.

\begin{tabular}{lcccccccc}
\hline Orientation & & Trial 1 & Trial 2 & Trial 3 & Trial 4 & Trial 5 & Trial 6 & Average \\
\hline \multirow{7}{*}{ Longitudinal } & $\begin{array}{c}R_{c}^{*} \\
\text { Hardness } \\
(\text { Ksi) }\end{array}$ & 26 & 26 & 25 & 26 & 26 & 25 & 26 \\
$\begin{array}{c}\text { Tensile } \\
\text { strength } \\
(\mathrm{MPa})\end{array}$ & 869 & 869 & 855 & 869 & 869 & 855 & 864 \\
& $\begin{array}{c}\text { Hardness } \\
\left(\mathrm{Kg} / \mathrm{mm}^{2}\right)\end{array}$ & 89 & 89 & 87 & 89 & 89 & 87 & 88 \\
& $\begin{array}{c}R_{c}^{*} \\
\text { Transverse }\end{array}$ & 26 & 27 & 26 & 27 & 27 & 25 & 26 \\
& $\begin{array}{c}\text { Hardness } \\
(\mathrm{Ksi}) \\
\text { Tensile } \\
\text { strength } \\
(\mathrm{MPa})\end{array}$ & 126 & 129 & 126 & 129 & 129 & 124 & 127 \\
& $\begin{array}{c}\text { Hardness } \\
\left(\mathrm{Kg} / \mathrm{mm}^{2}\right)\end{array}$ & 89 & 889 & 869 & 889 & 889 & 855 & 877 \\
\hline
\end{tabular}


ronment. The test specimens were deformed at a constant strain rate of 0.0001/sec. An axial 12.5-mm gage length clip-on type extensometer was attached to the test specimen at the gage section using rubber bands. The stress and strain measurements, parallel to the load line, and the resultant mechanical properties of stiffness, strength (yield strength and ultimate tensile strength), failure or fracture stress and ductility (quantified as strain-to-failure) was provided as a computer output by the control unit of the test machine.

\subsection{Failure analysis}

The fractures surface of the fully deformed and failed tensile test samples were comprehensively examined in the scanning electron microscope (SEM). The samples for observation were sectioned parallel to the fracture surface. The fracture surfaces were observed at different magnifications to determine the macroscopic fracture mode and to concurrently characterize the fine scale topography and the intrinsic features on the tensile fracture surface for the purpose of establishing microscopic mechanisms governing fracture during uniaxial deformation. The macroscopic mode refers to the overall nature of failure while the microscopic mechanisms relate to the local failure processes, such as: (i) microscopic void formation, (ii) microscopic void growth and eventual coalescence, and (iii) nature, intensity and severity of both the fine microscopic and macroscopic cracks.

\section{Results and discussion}

\subsection{Initial microstructure}

The microstructure of an alloy is an important factor that determines its hardness, tensile properties, fracture toughness and fatigue strength. The optical microstructure of the longitudinal sheet stock (figure 2) and transverse oriented sheet stock (figure 3 ) reveals that though the orientation of the microstructure is slightly different, they essentially have similar grain size and shape. Observations over a range of magnifications revealed the two distinctly different micro constituents in this Ti-Al-V-Fe-O $\mathrm{O}_{2}$ alloy to be the alpha $(\alpha)$ and beta $(\beta)$ phases. The grains of the alpha phase (light) were well distributed in the matrix of the transformed beta (dark phase). The presence of vanadium in the alloy helps in lowering the beta transus temperature. The presence of aluminum and oxygen stabilizes alpha $(\alpha)$ phase and increases the ultimate tensile strength where as iron, which aids in stabilizing the beta $(\beta)$ phase form binary system of the $\beta$-eutectoid type and there by improves hardenability and increase the response to heat treatment (Wessel 2004). The alloy sheet before being hot deformed from a cast metal or pre-deformed billet does not have a specified and stable structure, which determines the mechanical properties of the final structure. Before the final structure, which in essence is the multiphase metal that is formed, the alloy undergoes a polymorphic $(\alpha \leftrightarrow \beta)$ transformation and numerous metastable phase transformations during thermo-mechanical treatment. When the $\alpha+\beta$ phase undergoes deformation at regular rate new grain boundaries are formed at the boundaries of initial $\beta$-grain as well as in the inner regions and recrystallization may occur during cooling. Thus, the initial lamellar structure of $\alpha+\beta$ region is transformed into globular structure and the initial spheroidization of lamellar structure is achieved no less than $50-60 \%$ followed by annealing (Moiseyev 2006). Upon annealing the material at $760^{\circ} \mathrm{C}$, in a vacuum environment so as to minimize environmental interactions, a temperature that is high in the alpha and beta phase field, the intrinsic features, that is, the phases present in the microstructure upon gradual cooling to room temperature $\left(25^{\circ} \mathrm{C}\right)$, consists of primary alpha 

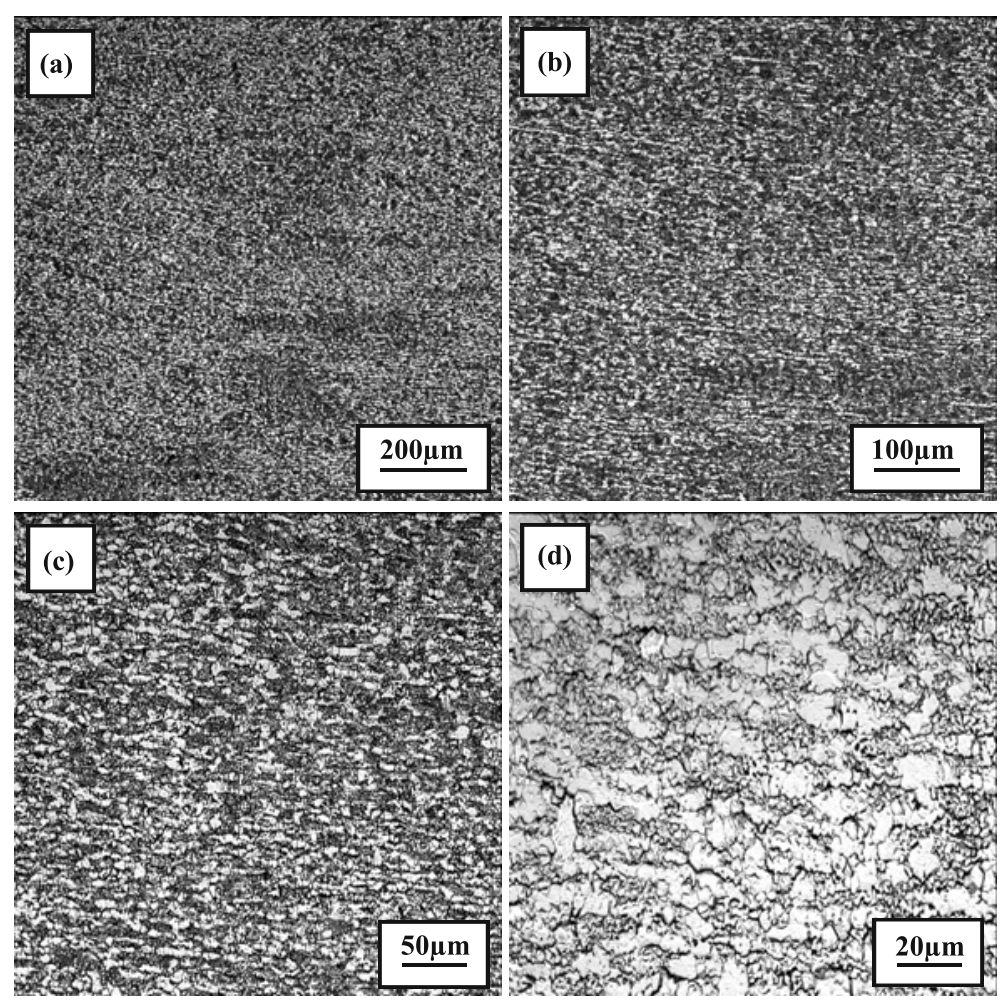

Figure 2. Optical micrographs showing the key micro-constituents in the cold rolled sheet (mill annealed) Ti-4 Al-2.5 V-1.5 Fe- $0 \cdot 25 \mathrm{O}_{2}$ alloy [ATI $425^{\mathrm{TM}}$ ] in the longitudinal orientation.

$(\alpha)$ and the transformed beta $(\beta)$. The large volume fraction of the alpha grains was predominantly non-uniform in size and shape. The net volume fraction of the beta phase was low when compared to the alpha phase.

\subsection{Hardness}

The Vickers microhardness measurements (table 2) show a variation in microhardness taken through a cross-section of both the longitudinal and transverse specimens of the as-received sheet stock of alloy ATI $425^{\mathrm{TM}}$. This is ascribed to intrinsic microstructural contributions, namely, the presence of both the alpha and beta phases. Further, it is seen that the hardness values when plotted reveal marginal spatial variability with an average value of $320 \mathrm{~kg} / \mathrm{mm}^{2}$ in the longitudinal orientation and $327 \mathrm{~kg} / \mathrm{mm}^{2}$ in the transverse orientation. This suggests that the alloy is marginally harder in the transverse orientation than in the longitudinal orientation. The measurements were made with accuracy and precision across the center of each sample mounted in bakelite in order to gather detailed information regarding spatial variability of the hardness while concurrently minimizing contributions from location of the indent. The measurements provide an idea about how the presence of both the alpha and beta phases can strengthen the alloy and also the impact and/or influence of the processing-related artifacts resulting in a concurrent weakening effect. The presence of processing-related artifacts, such as, the fine microscopic pores and voids, and fine microscopic cracks, when intercepted by the 

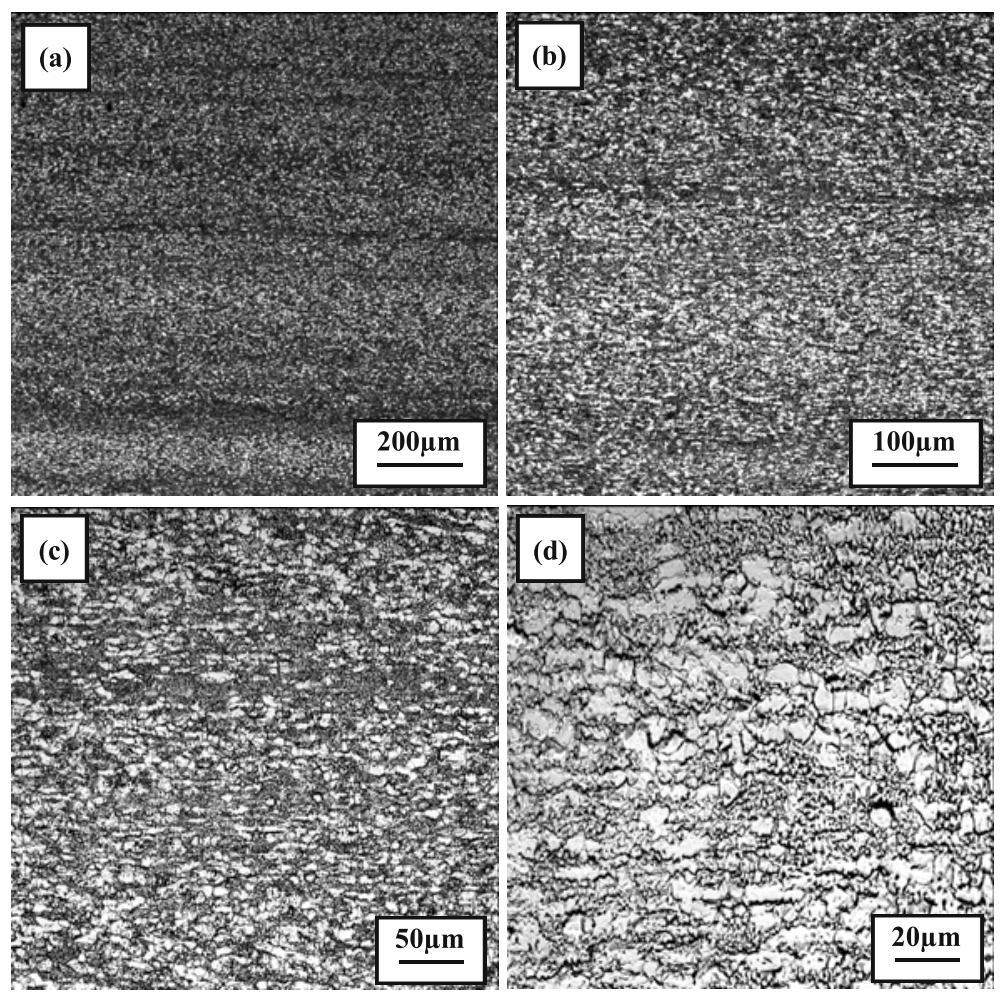

Figure 3. Optical micrographs showing the key micro-constituents in the cold rolled sheet (mill annealed) Ti-4 Al-2.5 V-1.5 Fe- $0 \cdot 25 \mathrm{O}_{2}$ alloy [ATI $425^{\mathrm{TM}}$ ] in the transverse orientation.

pyramidal indenter, will tend to cause a net decrease in the value of measured microhardness of the sample.

The macrohardness values (table 3 ), based on the Rockwell $\mathrm{C}$ scale, across the length of a machined test specimen gave an average value of $88 \mathrm{~kg} / \mathrm{mm}^{2}$ for the longitudinal specimen and $90 \mathrm{~kg} / \mathrm{mm}^{2}$ for transverse specimen. The micro-hardness values were noticeably higher than the macrohardness value across the length of the test specimen for both orientations of the as-provided sheet stock of alloy ATI $425^{\mathrm{TM}}$, as shown in figure 4. The observed lower value of the macrohardness of this titanium alloy is ascribed to the presence of a population of processing-related artifacts. The average values of both the microhardness and macrohardness measurements for the two orientations, i.e. longitudinal and transverse, are compared in the bar graph shown in figure 5, and reveals the micro-hardness, i.e. the local hardness, value of the alloy sample to be noticeably greater than the corresponding value of the macrohardness, i.e. global hardness, as expected.

\subsection{Tensile properties}

The room temperature tensile properties of the ATI $425^{\mathrm{TM}}$ alloy for both the longitudinal and transverse orientation of the as-provided sheet are summarized in table 4 . The results reported are the mean values based on duplicate tests. The elastic modulus, yield strength, ultimate tensile strength, elongation-to-failure $\left(\epsilon_{f}\right)$ and strength at failure (fracture, $\sigma_{f}$ ) were provided as an output of the PC-based data acquisition system. The yield strength was determined by 


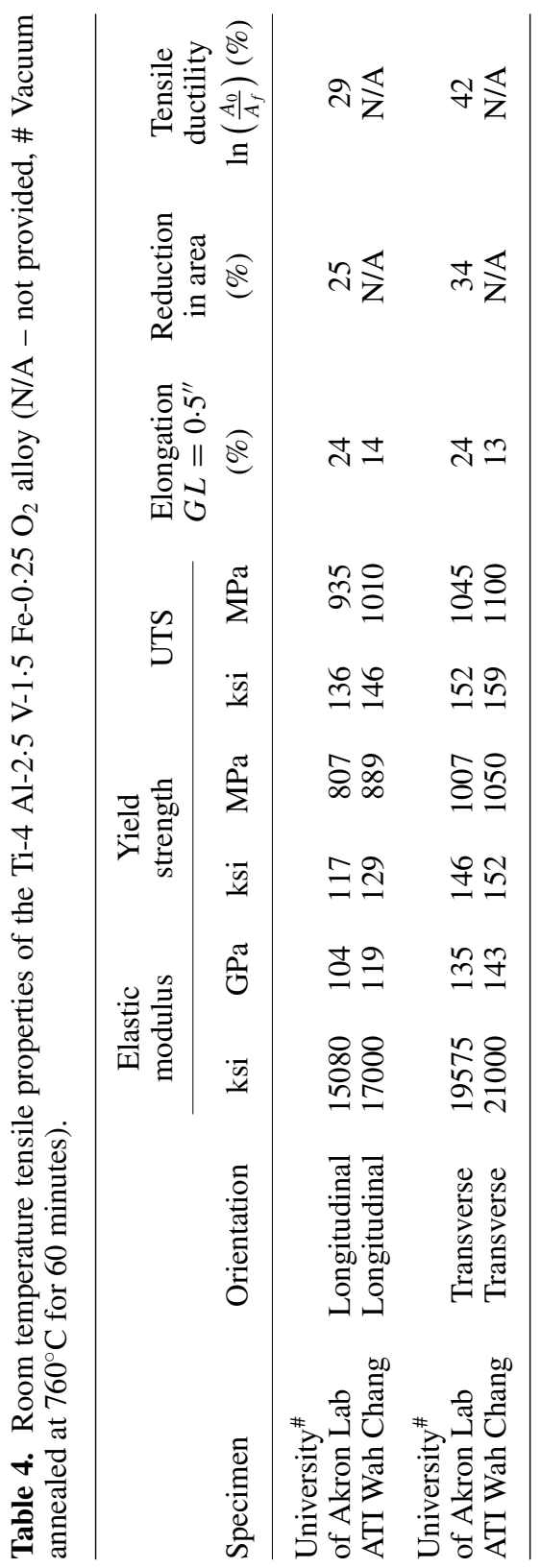




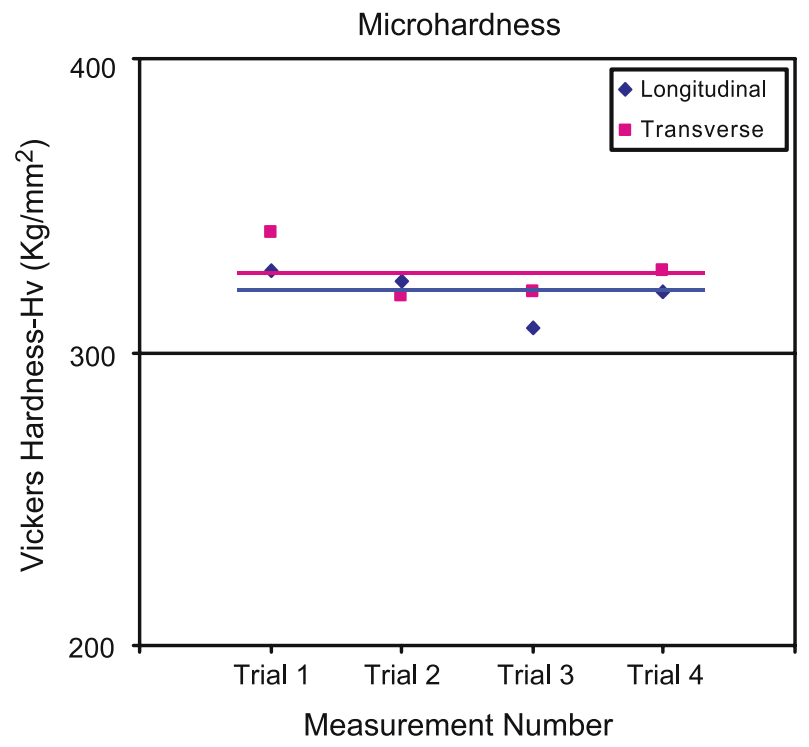

(a) Microhardness

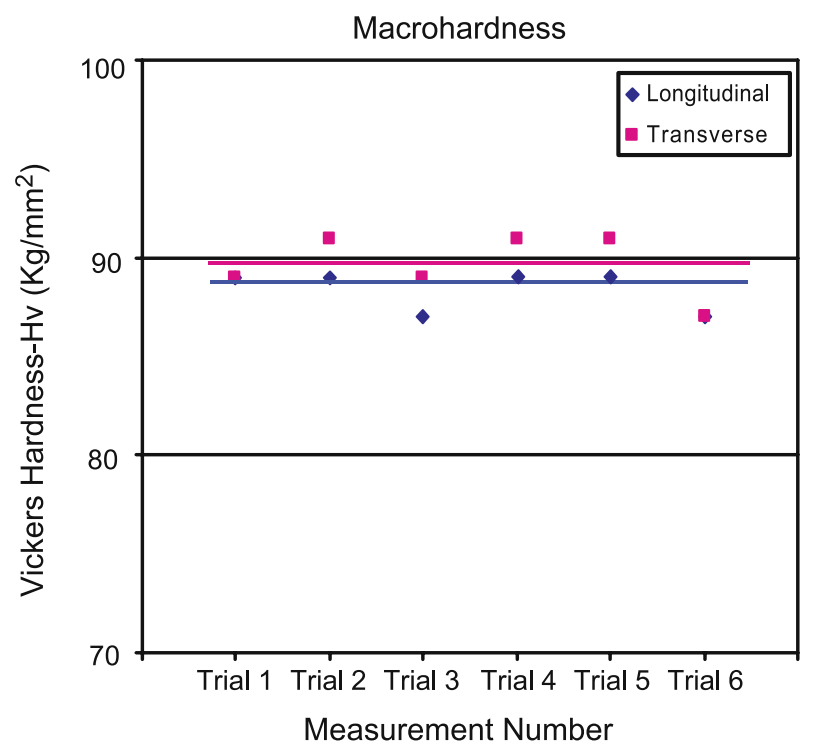

(b) Macrohardness

Figure 4. A profile showing the hardness values across the length of a cold rolled sheet (mill annealed) of the Ti-4 Al-2.5 V-1.5 Fe- $0.25 \mathrm{O}_{2}$ alloy [ATI $425^{\mathrm{TM}}$ ].

identifying the stress at a point on the engineering stress versus engineering strain curve where a straight line drawn parallel to the elastic portion of the stress versus strain curve at $0 \cdot 2 \%$ offset intersects the curve. The ductility is reported as elongation-to-failure over a gage length of $12.7 \mathrm{~mm}$. This elongation was measured using a clip-on extensometer that was attached to the gage section of the test specimen. Representative engineering stress versus engineering strain curve for the two orientations of the sheet, are shown in figure 6 . 


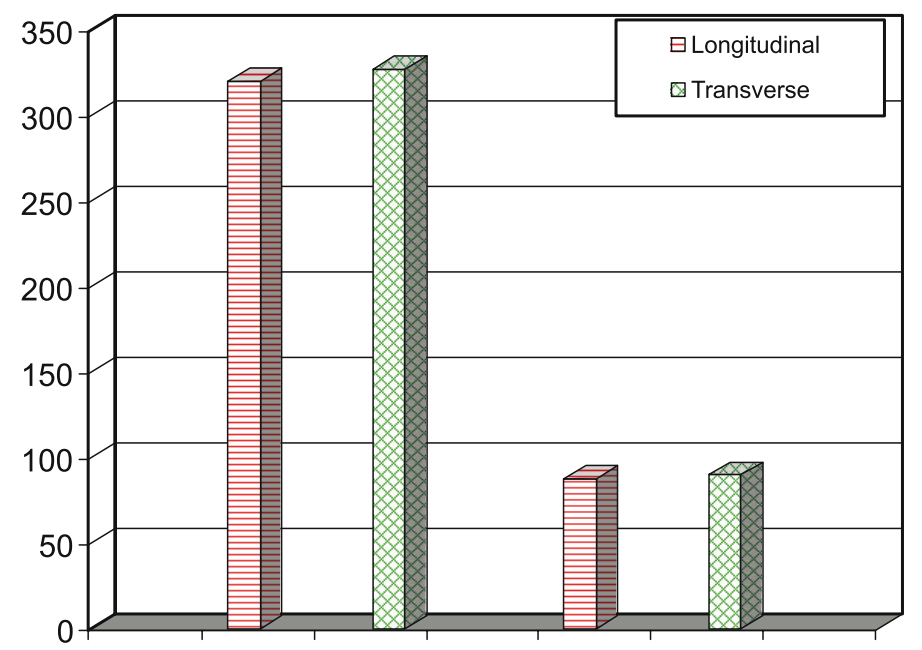

Figure 5. Bar graph depicting the average microhardness and macrohardness values for the cold rolled sheet (mill annealed) of the Ti-4 Al-2.5 V-1.5 Fe-0.25 $\mathrm{O}_{2}$ alloy [ATI $425^{\mathrm{TM}}$ ].

(a) A careful study of the tensile properties reveals that the test specimen taken from the transverse orientation has marginally higher values when compared to the test specimen machined in the longitudinal orientation of the sheet. The yield strength of the longitudinal test specimen, in the annealed condition, is $117 \mathrm{Ksi}$, which is only $9 \%$ lower than that of the commercial alloy Ti-6Al-4V. The yield strength of the transverse specimen is $146 \mathrm{Ksi}$, which is $14 \%$ higher than the longitudinal counterpart.

(b) The ultimate tensile strength of the longitudinal test specimen is $136 \mathrm{Ksi}$, which is $2 \%$ lower than the value for the commercial Ti-6Al-4V alloy. The tensile strength of the transverse specimen is $152 \mathrm{Ksi}$, which is $10 \%$ more than the longitudinal counterpart. For each orientation, i.e. longitudinal and transverse, the ultimate tensile strength of the alloy

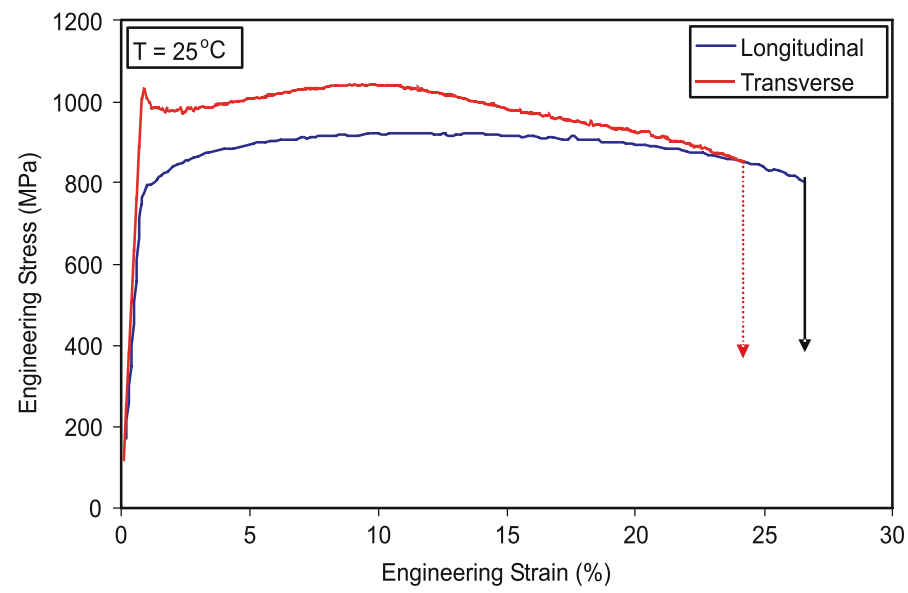

Figure 6. Engineering stress (MPa) versus engineering strain (\%) curve for the Ti-4 Al-2.5 V-1.5 Fe- $0 \cdot 25 \mathrm{O}_{2}$ alloy [ATI $425^{\mathrm{TM}}$ ]. 

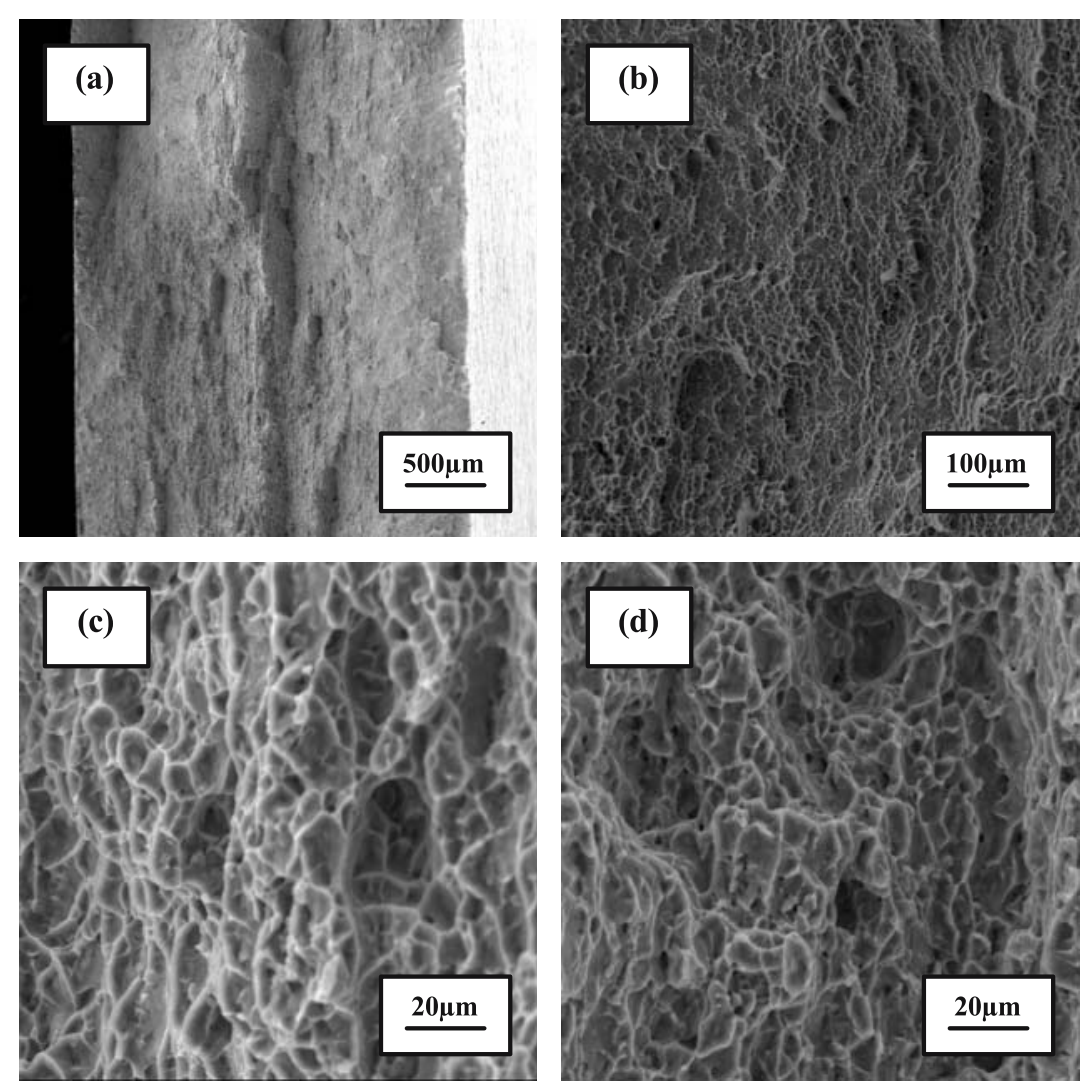

Figure 7. Scanning electron micrographs of the Ti-4 Al-2.5 V-1.5 Fe-0.25 $\mathrm{O}_{2}$ alloy [ATI $425^{\mathrm{TM}}$ ] deformed in tension showing: [Orientation: Longitudinal] (a) Overall morphology. (b) High magnification of (a) showing the transgranular fracture region. (c) High magnification of (b) showing a healthy population of dimples covering the transgranular fracture surface. (d) Fine microscopic voids and shallow dimples covering the region of tensile overload.

is marginally higher than the yield strength indicating the work hardening rate beyond yield to be low.

(c) The elongation-to-failure $\left(\epsilon_{f}\right)$ of both the longitudinal specimen and the transverse specimen of the alloy is $24 \%$, which is noticeably higher than that of the commercial alloy Ti-6Al-4V, by as much as $70 \%$.

The yield strength values of the alloy for both the longitudinal and transverse orientation of the alloy sheet conform to the values reported by the manufacturer (ATI Wah Chang). The values of ultimate tensile strength obtained in this study is $5-10 \%$ lower than the value reported by the material manufacturer. Also, the elongation-to-failure determined in this study is noticeably higher, by as much as $70 \%$, than the value reported by the material manufacturer.

\subsection{Tensile fracture behaviour}

An exhaustive examination of the tensile fracture surfaces of both the longitudinal and transverse specimens in a scanning electron microscope (SEM) revealed the specific role played by 

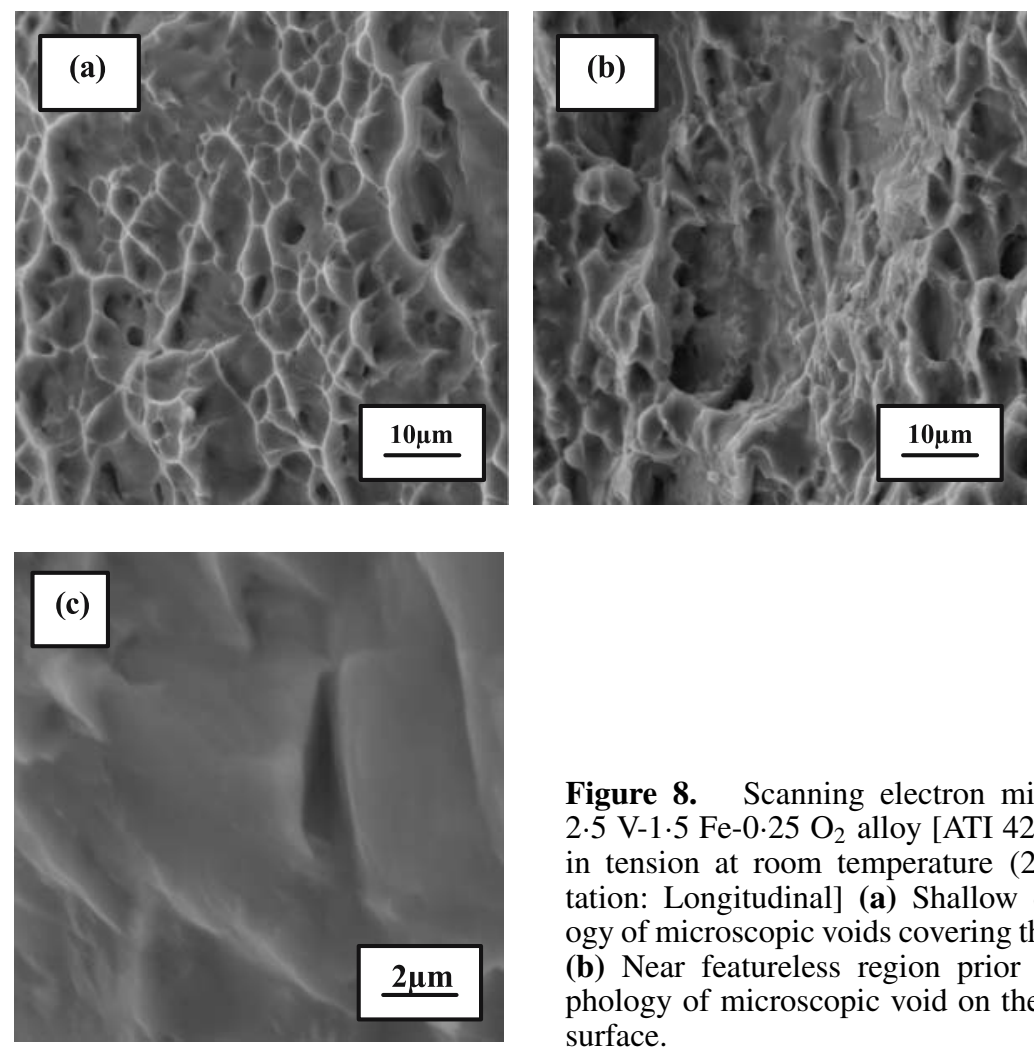

Figure 8. Scanning electron micrographs of Ti-4 Al$2.5 \mathrm{~V}-1.5 \mathrm{Fe}-0.25 \mathrm{O}_{2}$ alloy [ATI $425^{\mathrm{TM}}$ ] sample deformed in tension at room temperature $\left(25^{\circ} \mathrm{C}\right)$ showing [Orientation: Longitudinal] (a) Shallow dimples and morphology of microscopic voids covering the transgranular region. (b) Near featureless region prior to overload. (c) Morphology of microscopic void on the transgranular fracture surface.

intrinsic microstructural features and microstructural effects on strength and ductility properties of the titanium alloy. Representative fractographs of the tensile fracture surface of the titanium alloy sheet for the longitudinal orientation are shown in figures 7 and 8 , and for the transverse orientation figures 9 and 10 respectively.

At the macroscopic level, tensile fracture of the test specimen machined from the sheet stock was essentially by shear with the surface inclined at an angle to the far-field stress axis. Overall morphology of the tensile fracture surface appeared to be rough (figure 7a). Observation of the fracture surface at higher magnifications (figures $7 b$ and $7 c$ ) revealed a healthy population of dimples of varying size and shape covering the transgranular fracture surface. At the higher allowable magnification of the SEM a healthy population of fine microscopic voids and shallow dimples were found covering the region of tensile overload (figure 7d). Observation of the same fracture surface at a different location revealed the transgranular region to be covered with shallow dimples and randomly distributed fine microscopic voids. The region immediately prior to overload was near featureless as shown in figure $8 \mathrm{~b}$. The morphology of a fine microscopic void on the transgranular fracture surface at higher magnification is shown in figure 8c.

The fractographs of the test specimen machined from the transverse orientation of the as-provided sheet stock are shown in figures 9 and 10. The overall morphology was rough (figure 9a). The fine microscopic cracks were surrounded by a healthy population of dimples and voids that is reminiscent of both locally brittle and locally ductile failure mechanisms (figure 9b). At regular intervals deep-seated macroscopic cracks were evident on the fracture 

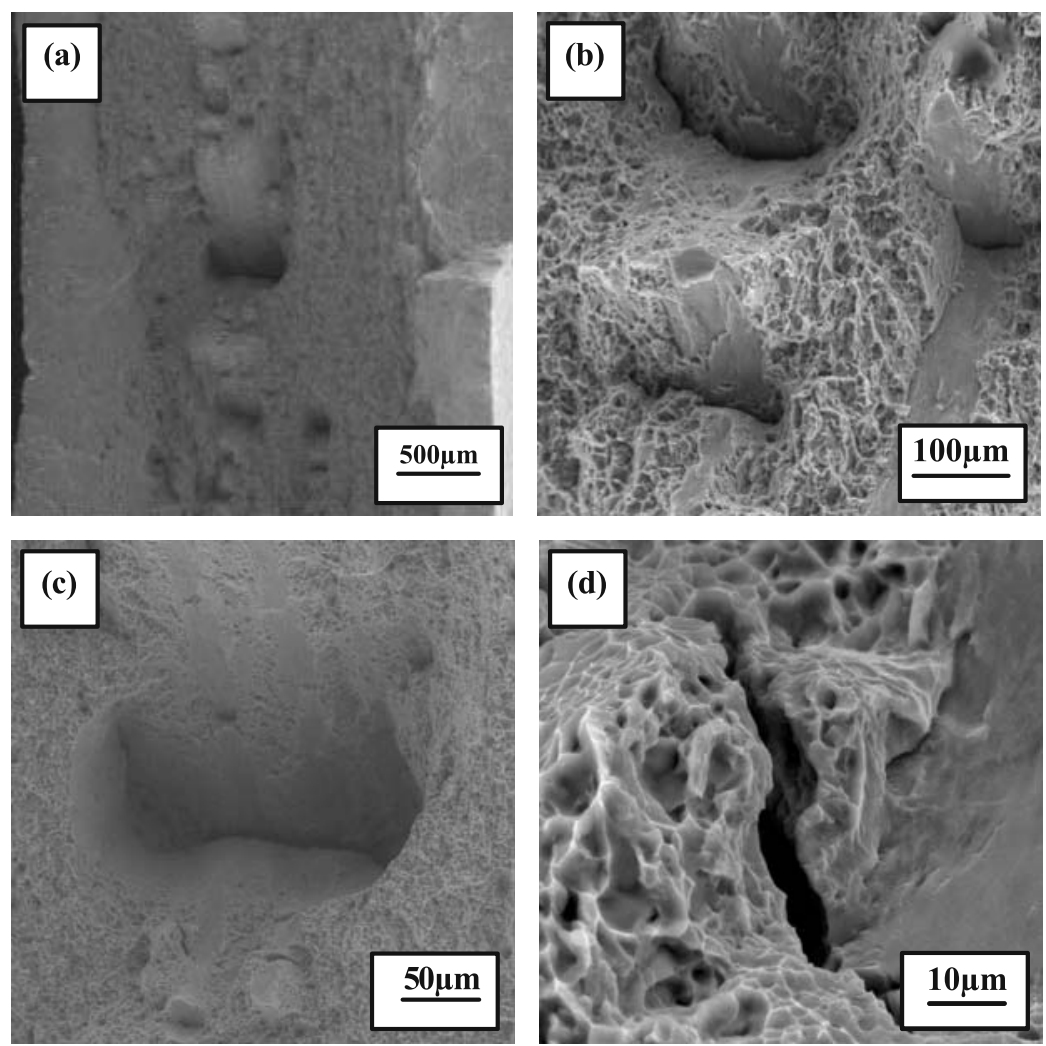

Figure 9. Scanning electron micrographs of the transverse specimen of the Ti- $4 \mathrm{Al}-2 \cdot 5 \mathrm{~V}-1 \cdot 5 \mathrm{Fe}-0 \cdot 25$ $\mathrm{O}_{2}$ alloy [ATI $425^{\mathrm{TM}}$ ] deformed in tension at room temperature $\left(25^{\circ} \mathrm{C}\right)$ showing: (a) Overall morphology of the fracture surface was rough. (b) High magnification of (a) showing an array of microscopic cracks. (c) A macroscopic cracks surrounded by a healthy population of dimples and voids. (d) A microscopic crack surrounded by voids and dimples on the overload surface.

surface (figure 9c). The overload region revealed a population of dimples of varying size and shape and fine microscopic voids. Overall, the presence of a population of fine microscopic voids and macroscopic voids coupled with isolated microscopic cracks contributes to lowering the actual strain-to-failure associated with ductile fracture. Isolated cracks in deep pockets, surrounded by a healthy population of dimples of varying size and fine microscopic voids was observed at the higher magnification (figure 9d). Observation of the transgranular surface region (figure 10a) revealed the fine microscopic cracks to be surrounded by a population of microscopic voids and dimples (figure 10b) reminiscent of locally brittle and ductile failure mechanisms. The dimples observed were of varying size but shallow in shape (figure 10c).

Due to the fairly high localized stress intensities, the corresponding strain favours the nucleation, growth and eventual coalescence of the fine microscopic and macroscopic voids to occur at low to moderate stress levels culminating in the early initiation and presence of microscopic cracks distributed through the fracture surface. During far-field loading the fine microscopic voids grow and eventually coalesce and the halves of these voids are the shallow dimples visible on the fracture surface. The fine microscopic cracks tended to propagate in the direction of the major stress axis, suggesting the important role played by normal stress 

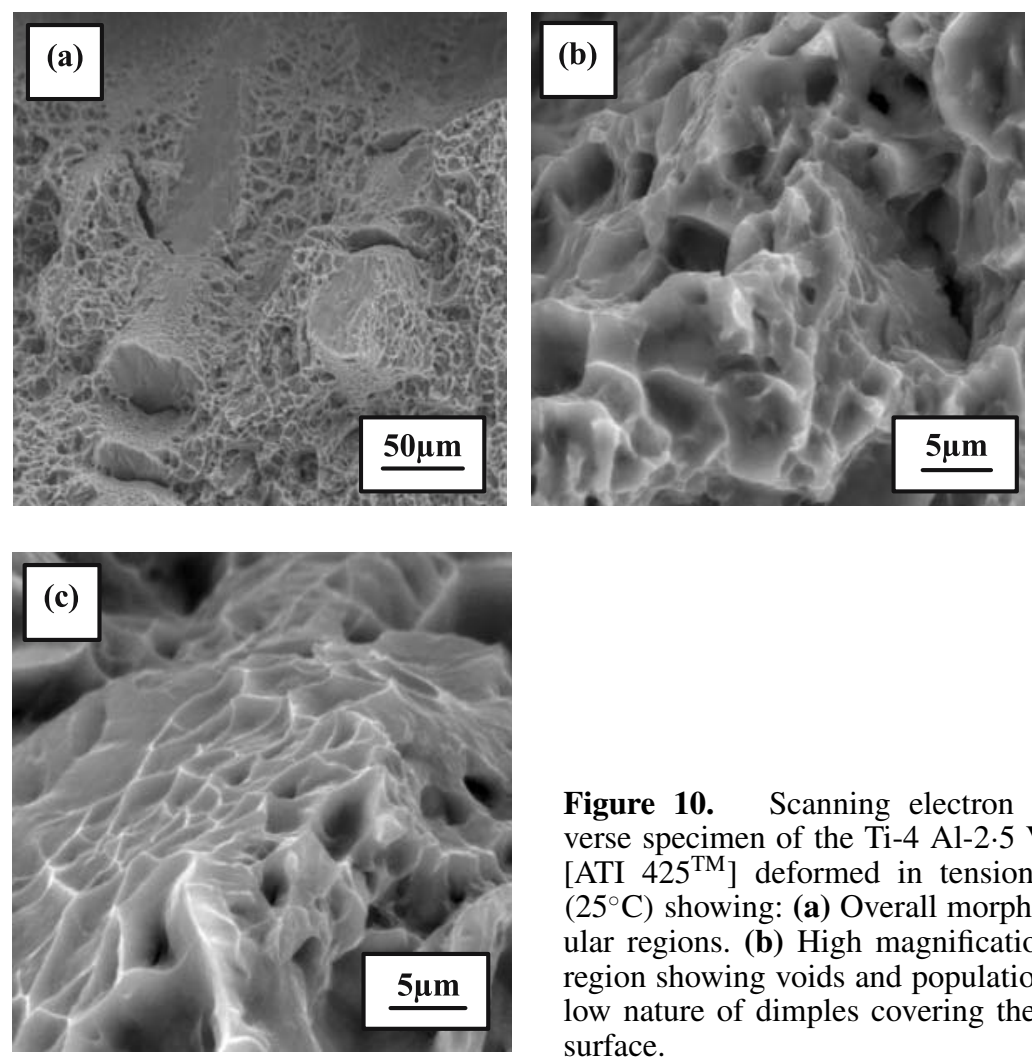

Figure 10. Scanning electron micrographs of transverse specimen of the Ti-4 Al-2.5 V-1.5 Fe- $0 \cdot 25 \mathrm{O}_{2}$ alloy [ATI $425^{\mathrm{TM}}$ ] deformed in tension at room temperature $\left(25^{\circ} \mathrm{C}\right)$ showing: (a) Overall morphology of the transgranular regions. (b) High magnification of the transgranular region showing voids and population of dimples. (c) Shallow nature of dimples covering the transgranular fracture surface.

in promoting tensile deformation. Since extension of the microscopic and macroscopic crack under quasi static loading occurs essentially at the high local stress intensities comparable with the fracture toughness of the material, the presence of a population of macroscopic and fine microscopic voids does exert a detrimental influence on the strain-to-failure associated with ductile fracture.

\section{Conclusions}

A fairly exhaustive study of the influence of orientation on microstructure, hardness, tensile deformation and final fracture behaviour of a Ti-4Al-2.5V alloy (ATI $425^{\mathrm{TM}}$ ) provided as sheet stock in the annealed condition provides the following key findings:

(i) The as-received alloy in the annealed condition has an alpha plus beta microstructure with the alpha grains of varying size and shape being well distributed in the beta matrix.

(ii) The microhardness and macrohardness measurements were consistent through the sheet specimen for both the longitudinal and transverse orientations. The microhardness and macrohardness data reveal the alloy to be harder in the transverse orientation than in the longitudinal orientation.

(iii) A comparison of the elastic modulus of this Ti-Al- $\mathrm{V}-\mathrm{Fe}-\mathrm{O}_{2}$ alloy for the two orientations, longitudinal and transverse, with the commercial Ti-6Al-4V alloy also in the annealed 
condition, reveals the longitudinal orientation of the sheet to be $9 \%$ higher than the commercial alloy while the transverse orientation is higher than the commercial alloy by $18 \%$.

(iv) The yield strength and tensile strength of this alloy, for both the longitudinal and transverse orientations, are comparable with the commercial alloy Ti-6Al-4V, within the limits of experimental scatter. The ultimate tensile strength of the alloy sheet is only marginally higher than the yield strength of the sheet indicating the tendency for strain hardening of the alloy beyond yield to be low.

(v) The alloy sheet in both the longitudinal (L) and transverse (T) orientations has adequate ductility, quantified in terms of elongation-to-failure, that makes it receptive and conducive for mechanical working operations.

(vi) The tensile fracture surface of the alloy sheet along the longitudinal [L] orientation revealed at the macroscopic level a fairly rough transgranular region and at microscopic level a healthy population of microscopic voids and shallow dimples of varying size and shape. For the transverse test specimen, the tensile fracture was macroscopically rough and globally at an inclination to the far field stress axis, reminiscent of ductile failure. However, microscopically the fracture surface was rough and covered with a healthy population of voids of varying size, dimples of varying size and shape, and isolated pockets of fine microscopic cracks, features reminiscent of locally ductile and brittle failure mechanisms.

\section{References}

Askeland D R (ed) 2007 The Science and engineering of materials, 2nd ed page 443 ASM Metals Handbook 1990 vol 2, 10th ed. Materials Park, Ohio, USA pp 586-591

Boyer R R 1996 An overview on the use of titanium in the aerospace industry. Materials Science and Engineering A213: 103-114

Donachie M J Jr. 2000 Titanium -A technical guide, 2nd ed. pp 1-3

Jacob J A, Kildoff T F (eds) 2004 Engineering materials technology, 5th ed. pg. 374

Moiseyev V N (ed) 2006 Titanium alloys: Russian aircraft and aerospace application. Taylor \& Francis, USA

Peters M, Kumpfert J, Ward C, Leyens C 2003 Advanced Engineering Materials 5(6): 419-427

Srivatsan T S, Kuruvilla M 2007 Microstructure, hardness, tensile deformation, cyclic fatigue and fracture behaviour of Ti-Al-V-Fe-O Alloy: Role of sheet stock. Final Technical Report, ATI Wah Chang

Titanium alloys developments 2006 Advanced Materials Processes

Wessel J K (ed) 2004 The Handbook of advanced materials. Oak Ridge, Tennessee, USA pp 272-319 